\title{
Perception of Nursing Students' Experience of Simulation Based Learning: An Application of Q-Methodology
}

\author{
Hyun Jung, Doo ${ }^{1}$ and Yun Jeong, Lee ${ }^{2,1^{*}}$ \\ ${ }^{1}$ Department of Nursing, JinJu Helalth College, 51 Uibyeong-ro, Jinju-si, \\ Gyeongsangnam-do, 52655, Republic of Korea \\ ${ }^{2}$ Department of Nursing , Kkottongnae University, 133, Sangsam-gil Hyeondo- \\ myeon, Seowon-gu, Cheongju-si, Chungcheongbuk-do, 28211, Republic of Korea \\ ${ }^{1}$ Prof.hjdoo@gmail.com, ${ }^{2}$ leeyj@kkot.ac.kr*
}

\begin{abstract}
The purpose of this study is to identify the Perception factors and structures of the nursing students' experience in simulation based leraning by using Q-methodology. 38 statements as a $Q$-sample are selected from the in-depth interview, and $P$-sample consists of 37 nursing students who experienced simulation based education. The 38 selected $Q$ statements from each of the 35 participants were classified into the shape of a normal distribution using a 9-point scale. Result: The collected data was analyzed using the pcQUANL program. The results revealed two discrete groups of students toward simulation based learning: 'The results suggest the perception factors of nursing students' experiences can be grouped into four categories: 'Recognizes of the nursing competency', 'Recognizes the importance of integrated nursing,' 'Recognizes the improved ability to handle emergency situations," and "Recognizes the transformed learning methods.' Conclusion: The findings revealed that teaching and learning strategies based on the four factors of attitudes could beneficially contribute to the customization of simulation-based learning.
\end{abstract}

Keywords: Nursing education, Nursing students, Patient simulation

\section{Introduction}

Following the development in the medical environment, the ability to make prompt and accurate clinical judgments and decisions as well as trained nursing services are becoming necessary in the nursing of a patient. The decisions made by a professional nurse are a result of critical thinking, which is an ability that is essential in evidence-based nursing practice and is an important skill at the core of evidenced-based nursing [1]. Thus, as it is difficult to achieve objectives in the science of nursing through lecture-style training only, clinical nursing training is mandatory. Clinical training does not stop at understanding the various information or concepts that nursing students require as a nurse, but goes on to train students on the nursing process and methods applicable to actual patients in need of care, helping the students to improve in their thoughts and attitude toward patients [2]. It ensures that nursing students are equipped with critical thinking skills and enhances their abilities for providing appropriate care after understanding the exact health problem of the patient.

However, due to the conditions of the site of the training as well as the conditions of the school, the current clinical fieldwork training holds many barrier factors in the gaining of various clinical experiences. Many of the times clinical training ends after observations or explanations as those in need of nursing refuse the practicing students from time to

\footnotetext{
${ }^{*}$ * Corresponding Author: Yun Jeong, Lee

E-mail.: leeyj@kkot.ac.kr,
} 
time for their lack of practical experience and other than simple tasks such as measuring vital signs, changing sheets, etc., the opportunities for nursing students to actually experience things for themselves are gradually decreasing [3, 4]. Consequently, simulation-based learning has emerged in order to resolve the problems of clinical training and to bridge the gap between theorized classes and clinical training [5].

Simulation-based learning combines various forms of education including multimedia technology, models, patients, and simulators, etc. and is a new educational strategy in the science of medicine and nursing that improves the safety of the patients. Simulation-based learning in nursing education is defined as a series of activities that imitate the real site of clinical practice, designed to enable critical thinking, decision making, and surgical procedures through methods such as interactive videos or use of equipment such as dummies [6].

Outside the country, training through the use of simulators is being emphasized and its effectiveness supported as a means of resolving the issue of medical mistakes made by medical personnel and health professionals [7].

According to a research conducted on the simulation of medical training by a simulation center in the United Kingdom, it was reported that $75 \%$ of nurses, medical personnel, and students in the clinical setting showed high levels of preference for simulation-based learning [8]. Domestically, simulation has been applied to the clinical training of a variety of fields in the clinical setting, such as neonatal emergency care [9], CPR emergency care $[10,11]$, intensive care $[12,13]$, maternal and obstetric care $[14,15]$, patient care for chronic obstructive pulmonary diseases and cardiac infarction [16], practical training for intravenous injections [17, nursing before and after operations [18], and emergency care for labored breathing [19], etc.

The advantages of such simulation practical training are that it enables the recreation of a variety of clinical settings in a safe environment that does not harm patients as well as the fact that it enables repeated learning and re-training by standardizing the necessary techniques. It also relieves the trainee's anxiety while letting the trainee gain clinical experience related to lecture content, study the areas of knowledge, technique, as well as attitude, and encounter cases that are inaccessible during clinical training [20]. In addition, it has been reported that the debriefing stage after the simulation-based learning is effective in cultivating the ability of critical thinking and instilling an understanding of the abilities of communication and clinical nursing practice in students, while also being effective in increasing motivation for clinical training, satisfaction with clinical training, and confidence [21]. On the other hand, as for the practical limitations simulation-based learning has, there is the issue of costs related to facilities, manpower, and equipment as well as the issue of how much the simulator can materialize of a real situation. Since there is also the problem of passive attitude, anxiety, and pressure, etc., during the participation of the training, arising from the trainee not being used to the simulation environment, elaborate scenarios and education experts are needed in order to overcome such limitations [22]. As indicated above, the simulation-based learning that is being utilized in practical training requires nursing students to change their learning attitudes from being passive to active and requires the students to switch their way of thinking. Therefore, it is crucial to examine how the nursing students are accepting and experiencing the new learning method of simulation-based learning.

Pertaining to qualitative research conducted domestically on simulation training in the science of nursing, there was a study that phenomenologically analyzed the experience of team-based simulation training among nursing students $[23,24]$ and a study that analyzed the types of debriefing in simulation medical training [25], but there has yet to be a subjective research conducted on analyzing the experience of simulation-based learning among nursing students using the Q methodology.

The Q methodology was a method developed by Stephenson [26] as a means of measuring the attitude, beliefs, and values of an individual. Its necessity and strong point 
lie in the fact that it can examine newly 'formed subjective viewpoints' through those who respond in accordance with the context when factors or variables cannot be presumed intuitively. People view the world, structuralize their experiences, make judgments, and behave based on a frame in which they make sense of their given environment. As an individual's cognitive framework is under the influence of circumstances and context, understanding the meaning of an event is impossible without apprehending the individual subjective frame in the right context [27]. Thus, it can be said for this research that utilizing the $\mathrm{Q}$ methodology for analyzing the subjective viewpoints formed from the experiences of the nursing students that participated in simulation-based learning is an appropriate method of study.

By grasping the cognitive framework of each of the nursing students on their experience of simulation-based learning, it can be seen that there are differences in how much importance an individual recognizes in something and how the individual accepts and reacts to that same something. This paper means to discuss simulation-based learning for existing nursing students in a different sense than that of preceding researches by defining the types of practical experience the nursing students had and clarifying the characteristics of each type as well as the differences between the types. Moreover, as simulation-based learning needs to be designed in a way that reduces the gap with clinical training [28], this research is anticipated to become useful in serving as preliminary data for the strategic development of inventing and increasing the utilization of step-by-step practice modules appropriate for the capability of the student and enhancing the level of student adaptability towards simulation-based learning.

\section{Study Aims}

The study aims to identify the perception nursing students have on simulation-based learning and to understand the structure and characteristics of said perception. It also aims to obtain preliminary data for improving the education of nursing students using simulation-based learning.

\section{Methods}

\section{Research Design}

This study applied a Q-methodological approach to explore and describe the perception of nursing students toward simulation based learning. Q-methodology is useful to explore each person's perception viewpoints and identify individual attitudes, feelings, perceptions, and values toward an object [Stephenson 1982], and is an appropriate research method to clarify nursing student's perception toward simulation based learning.

\section{Operating SBL}

Simulation refers to an educative device or method that can artificially reenact possible situations through mechanical operation or the use of a simulator in education or training. [29]. Simulation came into operation when Gaumard Scientific created NOELLE® S575.100 Tetherless Maternal and Neonatal Birthing Simulator. A simulator with the same size and anatomical structure as a pregnant woman was used to form an interactive relationship in terms of pathophysiological and pharmacological reactions as well as nursing intervention.

Simulation-based learning was implemented in a simulation lab similar to the obstetrical clinical setting. Simulation-based learning was conducted for two hours per week for one semester and the researcher operated the simulator in person.

\section{Research Procedure}

Construction of Concours ( Q Population) 
The Q-population was composed through the following process:

The first stage was a stage for assembling the Q-population. In this stage the references of previous researches were considered to gather statements related to the students' perception on SBL, called the Q-population.

The second stage was to obtain written narratives from nursing students. In this stage, 200 seniors were asked to fill out a questionnaire of the following three questions; 'How was the simulation training?', 'What are your thoughts on simulation training?', and 'What did you learn from the simulation training?'. The purpose and the process of the research were explained to students during the class and respondents were selected among volunteered students. To avoid repetition, 300 statements were extracted from the collected data. In-depth interviews were conducted with seven students in order to clarify the meaning of their statements and to check for any additional statements.

\section{Q-sample}

A total of 70 statements were reviewed and extracted by two professors to be selected as the Q-population. Statements under the same topic were classified into one category while the categories were also classified into the three categories of nursing knowledge, nursing performance, and communication.

Ultimately, 38 statements that were identified as the most representative and distinctive (with effective assessment functions) were deduced as Q-samples (Table 4).

Selection of participant (P-sample)

To collect P-samples for Q-sorting, senior students with SLB experience were selected in nursing colleges in Korea's Gyeongnam province.

As the Q methodology deals with not inter individual differences but intra individual differences in significance, there is no limit to the number of $\mathrm{P}$ samples and problems arise statistically when the number of samples grow to be too large [29]. Based on these facts and taking demographic characteristics into account, the P sample was selected by convenience sampling 35 nursing students (Table 1).

\section{Q-sorting}

35 participants produced 38 Q-statements with a rating on a scale of 1-9. Participants of Q-sorting were to read each of the cards with Q-statements and classify the statements they most agree with on +4 (9) and the statements they most do not agree with on -4 (1), gradually moving their way inward to finish in the neutral section. For the statements that were placed in the positive and negative poles $(-4,+4)$, the participants' reasons for selection were directly written up in order to examine the reasons why such statements were chosen and a follow-up interview was also conducted to clarify the meaning.

\section{Data analysis}

The pc-QUANL program was used to analyze the Q sorts. Relevant to the analysis of $\mathrm{Q}$ sorts was the following three points; using eigen values of at least 1.0 for the final interpretation, conducting varimax rotation in order to maximize the variance between each factor, and adopting Z-score as a measure of standard deviation (statements with a Zscore above +1.0 as positive views and below -1.0 as negative views). A best estimate for each factor was calculated using factor weightings that demonstrate the extent of an individual Q sort in each factor.

After the purpose and the process of the research were explained to the research participants, the participants voluntarily signed participant consent forms. It was explained that the participants could withdraw their participation in the research at any given period during the course of the research should they feel inclined to and that there would be no penalties whatsoever. It was also explained that the contents of the collected data would only be utilized for research purposes and that the personal information of the 
participants would be guaranteed. The ethical aspects of the participants were taken into much consideration through such procedures.

\section{Result}

After conducting Q-factor analysis, the perception of nursing students who received Simulation Based Learning was categorized into four Q-factors. These Q-factors explain $46.50 \%$ of all the variables, which each Q-factor explaining $20.50 \%, 9.86 \%, 8.42 \%$, and $7.72 \%$, respectively. Correlations between factors of subjectivity are as follows: 0.140 between the Factor 1 and Factor 2, 0.198 between Factor 1 and Factor 3, 0.327 between Factor 1 and Factor 4, 0.056 between Factor 2 and Factor 3, 0.152 between Factor 2 and Factor 4, and 0.296 between Factor 3 and Factor 4.

Factor 1: Recognizing the Nursing Competency

Factor 1 showed strong agreement on statements such as 'Nurses are required accurate skills and requires appropriate interventions, communication, and critical thinking competency $(Z=1.96)$ ', 'I was very inspired by my friends' communication abilities in nursing intervention. $(Z=1.81)$ ', 'I realized that I needed to acquire more knowledge in order to know what kind of direction the doctor is going to give $(\mathrm{Z}=1.80)$ ', 'I realized that it was possible for a lot of things to happen in the clinical setting. ( $Z=1.79)$ ', 'It was an opportunity for me to try the integrated application of the nursing interventions I've learned for each subject. ( $\mathrm{Z}=1.77)$.'

Factor 1 is characterized by those who recognize that nursing can only be complete after receiving a sound response from the patient and who experience that it is important to check and properly measure the results. Thus, Factor 1 is referred to as 'recognizes the Nursing Competency.'

Factor 2: Recognizing the importance of integrated nursing

Factor 2 is characterized by those who had experienced integrating their nursing knowledge of different subjects, topics and organs that they had learned during the simulated training. They recognized the importance of integrating knowledge from different subject. Thus, Factor 2 is named 'the factor that recognizes the importance of integrated nursing.'

Factor 2 had affirmative answers on statements such as 'It was an opportunity for me to try the integrated application of the nursing interventions I've learned for each subject $(Z=1.82)$ ', ' I realized that it was possible for a lot of things to happen in the clinical setting $(Z=1.54)$ ', ' I think the scenario for the entire process of the patient from hospital admission to discharge day will help. $(Z=1.42)$ ', 'I realized that everyone had different roles and competencies, such as senior nurses, new nurses, etc.( $Z=1.34)$ ', 'I realized that I needed to acquire more knowledge in order to know what kind of direction the doctor is going to give $(\mathrm{Z}=1.32)$.'

Factor 3: Improving the ability to handle emergency situations by training

Students in Factor 3 recognized that they have improved their ability to handle emergency situations by conducting simulated training on those situations, thereby gaining confidence. Factor 3 had more affirmative answers on statements such as ' I gained confidence as well as the ability to cope with emergency situations( $Z=1.75)$ ', ' It was a helpful experience that trained me in preparing for emergency situations and strengthened my ability to handle emergencies $(Z=2.11)$ ', 'I realized that the ability of educational intervention was important among the interventions of a nurse and that $\mathrm{I}$ needed to develop mine $(Z=1.14)^{\prime}$, ' I felt responsible towards the patient for not being able to provide the patient with appropriate care due to my lack of knowledge $(\mathrm{Z}=1.02)$.

Factor 4: Transforming learning methods 
Students in Factor 4 used to learn nursing by memorizing materials on or related to pathological physiology but recognized the importance of nurses' ability to properly assess the response and the status of a patient in a clinical environment. Thus, it is assessed that after receiving simulated training, they attempted to transform their learning methods.

Factor 4 students had affirmative answers on statements such as 'I realized that I needed to acquire more knowledge in order to know what kind of direction the doctor is going to give $(Z=2.32)$ ', 'Before the simulation training I used to focus on pathological physiology while studying, but since the simulation I now study by recalling the methods for assessing patient response and conditions or normal/abnormal symptoms $(Z=1.74)$ ', 'I thought that it was important to give good explanations to the patient and the guardian when nursing $(\mathrm{Z}=1.63)$ ', ' I learned that test results signify the conditions of the patient and that they form the basis for nursing intervention. $(\mathrm{Z}=1.50)$ It was an opportunity for me to try the integrated application of the nursing interventions I've learned for each subject $(Z=1.49)$ ', ' I realized that it was possible for a lot of things to happen in the clinical setting $(Z=1.26)$.'

T able 1. Factor Weights and Characteristics of Participant

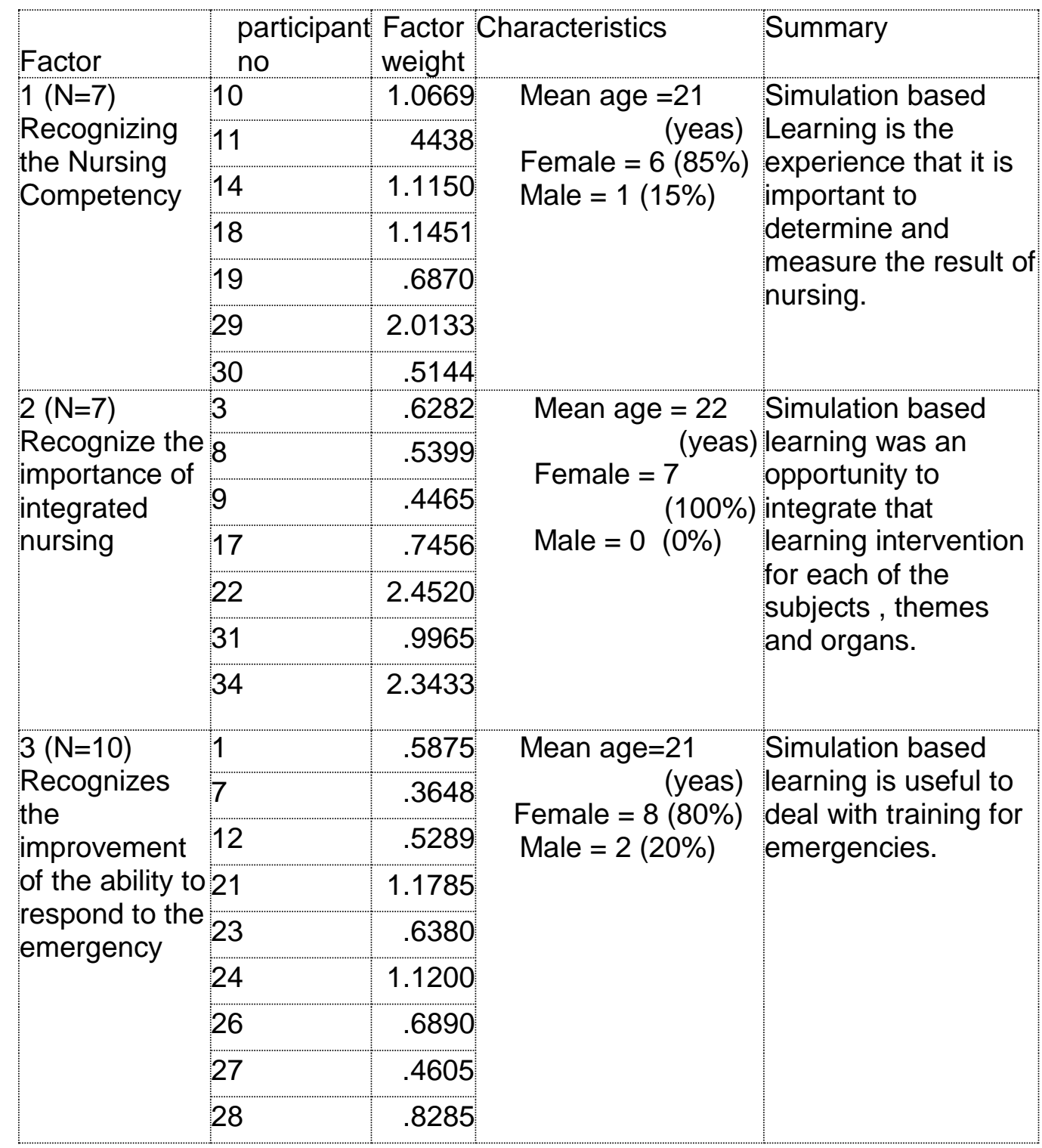




\begin{tabular}{|c|c|c|c|c|}
\hline & 35 & 1.2502 & & \\
\hline \multirow{11}{*}{$\begin{array}{l}4(\mathrm{~N}=11) \\
\text { Recognizes } \\
\text { the transform } \\
\text { of the learning } \\
\text { methods }\end{array}$} & 2 & .5296 & \multirow{11}{*}{$\begin{array}{c}\begin{array}{c}\text { Mean age }=21 \\
(\text { yeas }) \\
\text { Female }=9 \\
(82 \%)\end{array} \\
\text { Male }=2 \begin{array}{c}(18 \%) \\
\text { (18\%) }\end{array}\end{array}$} & \multirow{11}{*}{$\begin{array}{l}\text { Simulation based } \\
\text { learning has } \\
\text { brought a Transform } \\
\text { in learning methods. }\end{array}$} \\
\hline & 4 & 1.1060 & & \\
\hline & 5 & .7824 & & \\
\hline & 6 & .8128 & & \\
\hline & 13 & .9656 & & \\
\hline & 15 & 1.6558 & & \\
\hline & 16 & .3643 & & \\
\hline & 20 & 6302 & & \\
\hline & 25 & .5407 & & \\
\hline & 32 & .9725 & & \\
\hline & 33 & .9144 & & \\
\hline
\end{tabular}

Table 2. Q Statement and Typal Array of Z-scores

\begin{tabular}{|c|c|c|c|c|}
\hline \multirow[b]{2}{*}{ Item Q-Statement } & \multicolumn{4}{|c|}{ Z-score } \\
\hline & $\begin{array}{l}\text { factor1 } \\
(n=7)\end{array}$ & $\begin{array}{c}\text { factor2 } \\
(n=7)\end{array}$ & $\begin{array}{l}\text { factor3 } \\
(n=10)\end{array}$ & $\begin{array}{l}\text { factor4 } \\
(n=11)\end{array}$ \\
\hline $\begin{array}{l}\text { 1. I realized that the ability of educational } \\
\text { intervention was important among the } \\
\text { interventions of a nurse and that I needed to } \\
\text { develop mine. }\end{array}$ & 0.18 & 1.15 & 1.14 & 1.34 \\
\hline $\begin{array}{l}\text { 2. It was similar to actual situations and let me } \\
\text { have a realistic experience. }\end{array}$ & -1.18 & -1.07 & -0.21 & -1.51 \\
\hline $\begin{array}{l}\text { 3. It was a helpful experience that trained me } \\
\text { in preparing for emergency situations and } \\
\text { strengthened my ability to handle } \\
\text { emergencies. }\end{array}$ & -0.46 & -0.68 & 0.51 & -0.09 \\
\hline $\begin{array}{l}\text { 4. I think the scenario for the entire process of } \\
\text { the patient from hospital admission to } \\
\text { discharge day will help. }\end{array}$ & -1.04 & 1.42 & -0.73 & -0.58 \\
\hline $\begin{array}{l}\text { 5. I felt secure since it was a fictional situation } \\
\text { and all that was required of me was to try } \\
\text { my best. }\end{array}$ & -1.45 & 1.06 & -0.12 & -0.81 \\
\hline $\begin{array}{l}\text { 6. It was a meaningful experience to choose } \\
\text { the intervention appropriate for the patient's } \\
\text { symptoms, decide the order of priority } \\
\text { among the interventions to be applied, and }\end{array}$ & 1.01 & 1.07 & 0.54 & 0.47 \\
\hline
\end{tabular}




\begin{tabular}{|c|c|c|c|c|}
\hline actually apply them. & & & & \\
\hline $\begin{array}{l}\text { 7. It was meaningful how I got to experience } \\
\text { taking immediate interventions in response } \\
\text { to the situation at hand, instead of the } \\
\text { curriculum's uniform nursing practice. }\end{array}$ & 0.14 & 1.32 & 1.01 & .042 \\
\hline $\begin{array}{l}\text { 8. I realized that it was possible for a lot of } \\
\text { things to happen in the clinical setting. }\end{array}$ & 1.79 & 1.54 & -0.19 & 1.26 \\
\hline $\begin{array}{l}\text { 9. It was a worthwhile experience to solve a } \\
\text { problem with knowledge and resources that } \\
\text { are directly utilizable in the field. }\end{array}$ & -0.79 & 0.45 & 0.84 & 0.20 \\
\hline $\begin{array}{l}\text { 10. Ever since the simulation, when I come } \\
\text { across interventions in books I end up } \\
\text { imagining the situation where those } \\
\text { interventions would actually be applied in } \\
\text { the field. }\end{array}$ & -0.77 & -0.24 & -0.21 & 1.10 \\
\hline $\begin{array}{l}\text { 11. I became worried and lost my confidence } \\
\text { when I realized a patient could die if I didn't } \\
\text { provide him/her with proper nursing. }\end{array}$ & -0.19 & 1.12 & -1.67 & -1.84 \\
\hline $\begin{array}{l}\text { 12. I felt like an actual nurse working in a } \\
\text { clinical setting, rather than being a nursing } \\
\text { student. }\end{array}$ & -0.76 & 0.24 & -1.76 & -2.7 \\
\hline $\begin{array}{l}\text { 13. Before the simulation training I used to } \\
\text { focus on pathological physiology while } \\
\text { studying, but since the simulation I now } \\
\text { study by recalling the methods for } \\
\text { assessing patient response and conditions } \\
\text { or normal/abnormal symptoms. }\end{array}$ & 0.34 & 1.06 & 0.46 & 1.74 \\
\hline $\begin{array}{l}\text { 14. I realized that I needed to acquire more } \\
\text { knowledge in order to know what kind of } \\
\text { direction the doctor is going to give. }\end{array}$ & 1.80 & 1.32 & -0.42 & 2.32 \\
\hline $\begin{array}{l}\text { 15. I felt a sense of accomplishment when my } \\
\text { nursing produced good results. }\end{array}$ & 0.23 & -0.31 & 1.02 & 0.07 \\
\hline
\end{tabular}




\begin{tabular}{|c|c|c|c|c|}
\hline $\begin{array}{l}\text { 16. I thought that it was important to give good } \\
\text { explanations to the patient and the guardian } \\
\text { when nursing. }\end{array}$ & 1.61 & 1.01 & 0.63 & 1.63 \\
\hline $\begin{array}{l}\text { 17. I found that nurses have to know a lot, be } \\
\text { able to make quick judgments, and be good } \\
\text { at communicating }\end{array}$ & 1.56 & 0.57 & 0.79 & -0.28 \\
\hline $\begin{array}{l}\text { 18. I felt responsible towards the patient for } \\
\text { not being able to provide the patient with } \\
\text { appropriate care due to my lack of } \\
\text { knowledge. }\end{array}$ & 1.44 & 0.62 & 1.02 & -0.63 \\
\hline $\begin{array}{l}\text { 19. I felt proud of myself when I saw how well } \\
\text { I understood the situation and responded to } \\
\text { it. }\end{array}$ & 0.52 & 0.24 & -1.32 & -0.72 \\
\hline $\begin{array}{l}\text { 20. It was an experience where the team } \\
\text { adjusted different values to achieve a } \\
\text { unanimous decision. }\end{array}$ & 0.42 & -0.72 & 0.24 & -0.21 \\
\hline $\begin{array}{l}\text { 21. It helped me realize that it wasn't a matter } \\
\text { of being right or wrong, but was a matter of } \\
\text { different orders of priority in solving the } \\
\text { problem. }\end{array}$ & -0.20 & -0.70 & -1.11 & -1.17 \\
\hline $\begin{array}{l}\text { 22. Comparing my thoughts to the thoughts of } \\
\text { others made me look back on my own } \\
\text { values. }\end{array}$ & 0.03 & 0.24 & 0.31 & -0.73 \\
\hline $\begin{array}{l}\text { 23. I was very inspired by my friends' } \\
\text { communication abilities in nursing } \\
\text { intervention. }\end{array}$ & 1.81 & -0.92 & 0.61 & 0.59 \\
\hline $\begin{array}{l}\text { 24. Even if it isn't reflected in my grades, the } \\
\text { fact that others were watching made me } \\
\text { feel uncomfortable and pressured on its } \\
\text { own. }\end{array}$ & -01.6 & -1.0 & -1.55 & .8 \\
\hline $\begin{array}{l}\text { 25. It was an opportunity for me to try the } \\
\text { integrated application of the nursing } \\
\text { interventions l've learned for each subject. }\end{array}$ & 1.77 & 1.82 & -0.58 & 1.49 \\
\hline
\end{tabular}




\begin{tabular}{|c|c|c|c|c|}
\hline $\begin{array}{l}\text { 26. Nurses are required accurate skills and } \\
\text { requires appropriate interventions, } \\
\text { communication, and critical thinking } \\
\text { competency. }\end{array}$ & 0.13 & -1.6 & 0.32 & 0.74 \\
\hline $\begin{array}{l}\text { 27. I was able to grasp an understanding of } \\
\text { not only the patient, but the information and } \\
\text { situation surrounding the patient as well. }\end{array}$ & 0.13 & 0.42 & -0.70 & -0.10 \\
\hline $\begin{array}{l}\text { 28. I came to recognize the graphs and } \\
\text { figures of ECG, NST, etc. as symptoms of } \\
\text { the patient. }\end{array}$ & -0.13 & 0.14 & -0.21 & .80 \\
\hline $\begin{array}{l}\text { 29. I realized that everyone had differrent } \\
\text { roles and competencies, such as senior } \\
\text { nurses, new nurses, etc. }\end{array}$ & -0.19 & 1.34 & 0.09 & -0.21 \\
\hline $\begin{array}{l}\text { 30. I gained confidence as well as the ability } \\
\text { to cope with emergency situations. }\end{array}$ & 0.92 & -0.51 & 1.75 & -1.02 \\
\hline $\begin{array}{l}\text { 31. When my friends and I performed well with } \\
\text { each other, I felt like we became closer and } \\
\text { strengthened our friendship and } \\
\text { camaraderie. }\end{array}$ & 0.14 & -2.17 & 0.67 & 0.01 \\
\hline $\begin{array}{l}\text { 32. I learned that test results signify the } \\
\text { conditions of the patient and that they form } \\
\text { the basis for nursing intervention. }\end{array}$ & 0.11 & -0.61 & -1.69 & 1.50 \\
\hline $\begin{array}{l}\text { 33. I was impressed by the teams that were } \\
\text { good at giving explan -ations to the patient, } \\
\text { especially by those that were good at } \\
\text { commu-nicating. }\end{array}$ & -0.52 & -0.60 & 0.81 & 0.92 \\
\hline $\begin{array}{l}\text { 34. I was not able to respond quickly, because } \\
\text { I was only focused on prescribing and } \\
\text { missed the urgent symptoms instead. }\end{array}$ & 0.40 & 0.60 & -1.69 & -0.67 \\
\hline $\begin{array}{l}\text { 35. I used to focus on pathological physiology } \\
\text { before receiving the simulation training, but } \\
\text { learned the importance of symptoms and } \\
\text { nursing after the training }\end{array}$ & 0.71 & -1.31 & -.02 & .50 \\
\hline $\begin{array}{l}\text { 36. Seeing the patient get better from the } \\
\text { nursing treatments I assigned gave me }\end{array}$ & -1.53 & -1.6 & 0.51 & -0.89 \\
\hline
\end{tabular}




\begin{tabular}{|l|r|r|r|r|}
\hline reassurance and confidence. & & & \\
\hline $\begin{array}{l}\text { 37. I realized that the nursing activities I } \\
\text { perform would have to apply to actual } \\
\text { subjects. }\end{array}$ & -0.79 & 0.34 & 2.11 & -0.28 \\
\hline $\begin{array}{l}\text { 38. It taught me the communication method } \\
\text { for approaching patients. }\end{array}$ & -1.81 & -0.52 & 0.19 & -0.32 \\
\hline
\end{tabular}

\section{Discussion}

This research was conducted in order to explore the subjective types and characteristics of the experiences nursing students had while taking part in simulation training by means of the Q methodology. According to the results of the research, the nursing students' perceptions on their experience of simulation-based learning were 'gaining perception on nursing competency', 'gaining perception on integrated nursing', 'experiencing the management of emergency situations', and 'changing learning methods'.

Type 1 was the kind of students that gained perception on nursing competency. It can be assumed that these were the students that became aware of the professional capabilities of a nurse, such as the role of the nurse in a clinical setting, as well as their critical thinking abilities and communication skills, through their practical experience. During the simulation training these nursing students deemed it important to observe patient reactions in detail and logically deduce the meaning of such reactions based on existing knowledge and previous experiences so that a nursing diagnosis could be made. It seems as though type 1 students recognize the aforementioned process to be an important role of a nurse and a necessary capability.

Such characteristics of type 1 match up with the report that states how simulation training can be effective in developing the participant's confidence and competency [30] as well as the report that describes how students participating in simulation-based learning experience an expansion in their competency as a nurse, such as becoming more sensitive to patient reactions, acquiring more clinical knowledge, and gaining confidence [23]. This is also a result similar to the category of expansion in nursing competency out of the three categories deduced from the research of Kang, et al., a study that took a phenomenological approach to analyze the experiences of nursing students on their simulation training focusing on the cases of respiratory patients [23].

While recognizing the competencies of a clinical nurse, participants belonging to type 1 also asked questions on the limit to expressing competency, to which their teammates raised questions in response and had a subsequent discussion on the range and limit of the capabilities a nurse is able to show in the clinical setting through topics such as 'possible ways for nurses to deal with a medical staff's clinical judgment and prescription error' and 'cases of the application of psychological nursing intervention by medicine and surgery nurses'. Type 1 displayed the characteristic of recognizing the competencies of a nurse through the experience and wanting to have the competencies of a nurse ready. Accordingly, learning outcomes and various practicing modules that can strengthen and evaluate the competency of nursing students need to be developed.

Moreover, type 1 students expressed that they came to feel a sense of responsibility for the fact that the judgments they make based on their own knowledge are directly reflected on the conditions of the patient. This is a result contrary to the few research reports that found it difficult for students to learn how to treat patients from the simulation training as the simulation device only reminded them of a dummy and did not make the students treat 
it carefully like they normally would with actual patients [31]. Consequently, it is suggested that the effect on the sense of responsibility towards patients after practical training with standardized patients, instead of simulation-based learning, be verified through repeated study.

Type 2 was the kind of students that gained perception on integrated nursing and assigned importance to the simulation training's provision of an opportunity for students to not only observe patient responses but to make integrated judgments including the internal and external environments of patients. This result matches the deduction of 'growth of insight for clinical situations', made from Lee's studies [34].

Simulation-based learning has educative significance in the development of insight for clinical situations and the cultivation of the ability to think critically in clinical settings based on the aforementioned developed insight. The fact that nursing students were able to realize the integrated nature of a nurse's decision making and nursing activities on their own through simulation-based learning is one of the important learning outcomes of simulation training. However, based on previous reports of students not showing remarkable growth in their decision making ability when evaluated immediately after training as well as displaying a singular form of decision making behavior during the course of training, such as focusing on one clue at a time and then moving on to the next clue [32], repeated training of integrating information in the decision making process seems necessary.

Type 3 recognized simulation-based learning as an extremely helpful way of learning how to quickly handle emergency situations when nursing in a clinical setting. Type 3 students asserted that they gained confidence in the handling and nursing of emergency situations through simulation-based learning. This is an outcome that corresponds to the report on how more nursing performances build more confidence and are more effective in the competency development of the participant [31]. It also has things in common with the report that names simulation-based learning as extremely useful in the handling of emergency situations as simulation training provides an opportunity for new nurses and nursing students with few clinical experiences to practice in a safe environment with no ethical issues when training for ways to handle high-risk situations like cardiac arrest and emergency care, while giving feedback on the participant's performance until he or she is able to achieve a variety of skills proficiently [32].

In the clinical setting, nurses are expected to adapt to an evidence-based clinical practice and to develop skills for emergency situations [33]. The present clinical setting where the human rights of patients are emphasized only provide nursing students with observation-oriented clinical training, which is why simulation training is expanding as an alternative for overcoming such limitations of clinical training. In other words, the fact that simulation training provides an environment similar to the clinical setting is being reported as the key effect of simulation trainings [34]. There are, however, some cases reported of negative student experiences, such as the generation of anxiety, in terms of the simulation learning method [35]. As the intensity and influence of this ironic effect is insignificant when compared to the positive educative functions of simulation, such negative experiences were either reported as inevitable or simply strayed away from and it was said about them that interpreting them as a weakness in need of change was not advisable [35].

Participants of this research, too, stated that they felt anxiety while debriefing. After discussing about the anxiety felt during debriefing, the students said, "Emergency situations in the clinical setting are bound to bring about anxiety anytime and it is meaningless to try and control the anxiety itself. This sense of anxiety arises from not knowing what to do in an emergency situation. Only accurate information on the actions to take in that situation will be able to relieve it." In other words, the students summarized that the best way of overcoming the anxiety was to promptly handle the situation and that being anxious in an emergency situation was natural. This goes hand in hand with 
previous studies that found information on how to deal with the situation to be the most important factor and that such information could also resolve the anxiety [32].

Therefore, it seems necessary that systematic training be provided through the development of detailed manuals or protocols on nursing activities during an emergency situation. Moreover, considering the reports of a decrease in satisfaction from the repetition of identical cases [35], different modules with the application of situational levels of difficulty in the nursing performance and handling of emergency situations need to be developed, even if all of the modules end up falling under the same category of modules for emergency situations.

The main characteristic of type 4 students was the change in their learning methods. Type 4 students recognized on their own that their method of learning had changed for other nursing related classes as well after they had gone through practical training. This type of students deemed it very valuable that they had the chance to experience how nursing knowledge comes to be utilized in a clinical setting and claimed that after receiving simulation-based learning, they began to place more importance on the way to evaluate a patient's symptoms and the meaning behind the diagnosis tests when studying for theory classes. This is a result that matches the report of the boost in academic motivation after the simulation training [35] as well as the report of the increase of interest in one's major field of study after the enhancement of the ability of integrative thinking [36].

Although the learner's method of learning generally has stability, there could be a qualitative change following maturation and environmental stimulation and the learner could end up focusing his or her attention on how to interpret and put meaning into his or her experiences and learning content [37-38]. Even if the participant's decision making ability to deduce a clear nursing diagnosis and take the appropriate actions were falling short during the time of the simulation training, it seems that such deficiency can result in better studying habits in the future as well as higher interest in the participant's major field of study.

\section{Strengths and Limitations}

This research offers a variety of strong points. Strategies for teaching and learning can be utilized based on each of the factors. The factors and statements confirmed from the students' perspective can be utilized as valuable data when designing simulation-based learning in the future.

Despite such strong points, the fact that the nursing students took part in the research and conducted simulation-based learning for only one semester will serve as a limitation. The perception on simulation-based learning needs to be researched again in the future after various scenarios have been experienced or the training conducted repeatedly for a long period of time.

\section{Conclusion}

This research was written in an attempt to explore the subjective factors and their characteristics using $Q$ methodology on the experience of nursing students who participated in the simulated Based Learning

After conducting Q-factor analysis, the perception of nursing student's Experience of SLB was categorized into four Q-factors.

These Q-factors explain $46.50 \%$ of all the variables, which each Q-factor explaining $20.50 \%, 9.86 \%, 8.42 \%$, and $7.72 \%$, respectively. The results suggest the subjective factors of nursing students' experiences can be grouped into four categories: 'Recognizes of the nursing competency', 'Recognizes the importance of integrated nursing,' 'Recognizes the improved the ability to handle emergency situations," and "Recognizes the transformed the learning methods.' 
Results prove to be meaningful in that the research, rather than focusing on finding which factors contributed to nursing students' experiences on simulated training and measuring the effects of specific learning methods, focused on the subjectivity of nursing students' experiences in simulated training.

\section{Recommendation for Further Research}

As this research just examines the types of the perception on simulation-based learning, modules reflecting the characteristics by type as well as educational needs of students need to be developed, and a further study on the effects of the actual operation of the simulation-based learning curriculum are required.

The necessity of strategic development for enhancing the nursing students' adaptability towards simulation-based learning is suggested.

\section{Acknowledgments}

This paper is revised and expanded version of paper entitled [Awareness of Nursing Students' Experience of Simulation Based Learning: An Application of Q-methodology presented] at [The Second International Mega-Conference on Green and Smart Technology (GST 2015), Republic of Korea., Jeju, December, 2015 ]

\section{References}

[1] C. D. Scott and R. E. Smalley, "Diagnostic Ultrasound: Principles and Instruments", Journal of Nanosci. Nanotechnology, vol. 3, no. 2, (2003), pp. 75-80.

[2] H. S. Kim, "A Study on Relationship between Stress of Clinical Practice and Clinical Compe tency in Nursing Students", Journal Korea Community Health Nursing Academic Society., vol. 16, no. 1, (2002), pp. 64-76. doi: 10.5172/conu.14.2.145

[3] J. I. Kim, et al., "Study on the Present Status of Practicum of Fundamentals of Nursing and Test for Competency of Nursing Skills", The Journal of Fundamentals of Nursing, vol.17, no. 3, (2010), pp. 362370. DOI:http://society.kisti.re.kr/sv/SV_svpsbs03V.do?method=view.

[4] H. R. Kim and E. J. Choi, "Development of a Scenario and Evaluation for SimBaby Simulation Learning of Care for Children with Fever in Emergency Units", The Journal of the Korea Contents Association, vol. 11, no. 6, (2011), pp. 279-288, DOI:http://dx.doi.org/10.5392/JKCA.2011.11.6.279.

[5] J. J. Ignacio, "Evaluation of simulation learn ing for clinically-experienced nurses", Singapore Nursing Journal, vol. 39, no. 1, (2012), pp. 19-26.

[6] P. R. Jeffries, "Designing, Implementing, and Evaluating Simulations Used as Teaching Strategies in Nursing", Nursing Education Perspective, vol. 26, no. 2, (2000), pp. 96-103,

[7] T. Monhan, "Simulation workshop in changing general hospital", Laerdal, (2002), pp. 8-9.

[8] C. S. Bearnson and K. M. Wiker, "Human patient simulators: A new face in baccalaure ate nursing education at Brigham Young Uni versity”, Research Brief, vol. 44, no. 9, (2005), pp. 421-425.

[9] S. Y. Yoo, "Development and effects of simul ation-based education program for newborn emergency care", Journal of Korean Academy of Nursing, vol. 43, no. 4, (2013), pp. 468-477, DOI:http://dx.doi.org /10.4040/jkan.2013.43.4.468.

[10] Y. H. Kim and K. S. Jang, "Effect of a Simulation-based Education on Cardiopulmo nary Emergency Care Knowledge Clinical Performance Ability and Problem Solving Process in New Nurses", Journal of Korean Academy of Nursing, vol. 41, no. 2, (2011), pp. 245-255, Doi:http://dx.doi.org/10.4040/jkan.2011.41.2.245.

[11] E. N. Ryoo, E. H. Ha and J. Y. Jo, "Comparison of Learning Effects using High -fidelity and Multimode Simulation: An Application of Emergency Care for a Patient with Cardiac Arrest.", Journal of Korean Academy of Nursing, vol. 43, no. 2, (2013), pp. 185-193, DOI:http://dx.doi.org// 10.4040/jkan.2013.43.2.185.

[12] Y. H. Kim, Y. M. Kim and S. Y. Kang, "Implementation and Evaluation of Simulation Based Critical Care, Nursing Education Used with MicroSim", Journal of Korean Academy of Nursing, vol. 16 no. 1, 24-32, (2010), pp. 24-32, DOI : 10.5977/JKASNE.2010.16.1.024.

[13] S. J. Jang, E. O. Kwon, Y. O. Kown and H. K. Kown, "The Effects of Simulation Training for New Graduate Critical Care Nurses on Knowledge, Self-efficacy, and Performance Ability of Emergency Situations at Intensive Care Unit”, Korean Journal of Adult Nursing, vol. 22, no. 4, (2010), pp. 375-383. http://society.kisti.re.kr/sv/SV_svpsbs03V.do ?method=view. 
[14] S. E. Lee, "Evaluation of the Standardized Patients(SP) Managed Instruction for a Clinical Maternity Nursing Course", Journal of Korean Academy Society Nursing Education, vol. 17 no. 1, (2011), pp. 1424, DOI:http://dx.doi.org/10.5977/JKASNE.2011.17.1.014.

[15] W. S. Lee and M. O. Kim, "Effects and Adequacy of High-Fidelity Simulation-Based Training for Obstetrical Nursing", Journal of Kore an Academy of Nursing, vol. 41, no. 4, (2010), pp. 433-443, DOI:http://dx.doi.org/10.4040/jkan.2011.41.4.433.

[16] J. J. Yang, "The Effects of a Simulation -Based Education on the Knowledge and Clini cal Competence for Nursing Students," Journal of Korean Academy Society Nursing Education, vol. 18, no. 1, (2012), pp. 14-24, DOI:http://dx.doi.org/10.5977/jkasne.2012.18.1.014.

[17] E. Y. Jung, "Evaluation of Practical Exercises Using an Intravenous Simulator Incorporating Virtual Reality and Haptic Technologies", Unpublished doctoral dissertation, Ajou University, Sowon, (2011), pp. 47-49.

[18] J. H. Kim, I. H. Park and S. J. Shin, "Systematic Review of Korean Studies on Simulation within Nursing Education", The Journal of Korean Academic Society of Nursing Education, vol. 19, no. 3, (2013), pp. 307-319, DOI:http://dx.doi.org/10.5977/jkasne.2013.19.3.307.

[19] H. K. Hur and S. M. Park, "Effects of simulation based education, for emergency care of patients with dyspnea, on knowledge and performance confidence of nursing students", Journal of Korean Academy Society Nursing Education vol. 18, no. 1, (2012), pp.111-119, DOI:http://dx.doi.org/10.5977/jk asne.2012.18.1.111.

[20] R. P. Cant and S. J. Cooper, "Simulation- based learning in nurse education: Systematic review", Journal of Advanced nursing, vol. 66, no. 1, (2012), pp. 3-15, DOI:http://dx.doi.org/10.1111/j.13652648.2009.05 240.x.

[21] K. T. Dreifuerst, "The essentials of debri efing in simulation learning: A concept analysis", Nursing Education Perspectives, vol. 30, no. 2, (2009), pp.109-114, DOI:http://dx.doi.org/10.1043/1536-5026030.002.0109.

[22] S. O. Lee, M. R. Um and J. H. Lee, "Use of Simulation in Nursing Education", The Journal of Korean Academic Society of Nursing Education, vol. 13, no. 1, (2007), pp. 90-94. http://society.kisti.re.kr/sv/SV_svpsbs03V.do?method=view.

[23] H. Y. Kang, E. Y Choi and H. R. Kim, "Nursing student's experiences in team based simulation learning", The Journal of Korean Academic Society of Nursing Education, vol. 19, no. 1, (2013), pp. 515, DOI:http://dx.doi.org/10.5977/jkasne.2013.19.1.5.

[24] S. E, Jung and S. H. Lee, "Nursing Student's Experience of Education using Simulation ", Qualitative Research, vol. 11, no. 1, (2012), pp. 50-59.

[25] A. Y. Lee, J. K. Kim, E. J. Lee and B. H. Kim, "A Typology of the Participant' Perceptions on Debriefing in Simulation Based Health Care Education", Journal of Human Subjectivity, vol. 27, (2013), pp. 113-127, http://dbpia.co.kr/view/ar_view.asp?arid=2385081.

[26] W. Stephenson, "Study of Behavior: Q-Techn ique and its Methodology", Chicago: The University of Chicago Press, (1953).

[27] S. M. Hwang and E. H. Choi, "The implementation of Q-methodology in psycho logical research and the interpretation of its result: The duet of objectivity and subjectivity", Journal of Human Subjectivity, vol. 7, (2002), pp. 4-26.

[28] D. L. Rodgers, S. Securro Jr. and R. D. Pauley, "The effect of high-fidelity simulation on edu cational o utcomes in an Advanced Cardio vascular Life Support course", Simulation in Healthcare, vol. 4, no. 4, (2009), pp. 200-206, DOI: 10.1097/SIH.0b013e3181b1b877.

[29] H. G. Kim, "Q-methodology", Seoul: Communication Books, (2008).

[30] E. A. Olejniczak, N. A. Schmidt and J. M. Brown, "Simulation as an orientation strategy for new nurse graduates: An integrative review of the evidence", Simulation in Health care, vol. 5, (2012), pp. 52-57, DOI:http://dx.doi.org/10.1097/SIH.0b013e3181ba1f61.

[31] P. Baxter and G, Norman, "Self-assessment or self deception? A lack of association between nursing students' self-assessment and performance", Journal of Advanced Nursing, vol. 67, no. 11, (2011), pp. 2406-2413, DOI:http://dx.doi.org/10.1111/j.1365-2648.2011. 05658.x.

[32] J. Scholes, R Endacott, M. Biro, B. Bulle, S. Cooper, M. Miles, C. Gilmour, P. Buykx, L. Kinsman, R. Boland, J. Jones and F. Zaidi1, "Clinical decision-making: midwifery students' recognition of and response to, postpartum haemorrhage in the simulation environment", vol. 12, no. 1, (2012), pp. 1-12, DOI:http://dx.doi.org/ 10.1186/1471-2393-12-19.

[33] D. Perkins, "Simulation in resuscitation training", Resuscitation, vol.73, no. 2, (2007), pp. 202-211.

[34] J. H. Lee and M. N. Choi, "Evaluation of Effects of a M.S. "Graduating nurses' self- evaluation of information technology competencies", vol. 48, no. 2, (2009), pp. 86-90, DOI:2009/03doi/ref/10.7748/ns2009.02.23.22.35.c6776.

[35] K. Lasater, "High fidelity simulation and the development of clinical judgement: students' experiences", The Journal of Nursing Education, vol. 46, no. 6, (2007), pp. 269-276.

[36] I. S. Kho, H. S. Kim,I. S. Kim, S. S. Kim, E. K. Oh, E. J. Kim, J. H. Lee and S. W. Kang, "Development of a Scenario and Evaluation for Simulation Learning of Care for Patients with Asthma in Emergency Units", The Journal of Fundamentals of Nursing, vol. 17, no. 3, (2010), pp. 371-381. 
[37] K. J. Ahn, "Learning Styles and Preferred Learning Methods of Undergraduate Nursing Students", The Journal of Korean Academic Society of Nursing Education, Find all citations in this journal (default), vol. 13, no. 1, (2007), pp. 13-22, http://society.kisti.re.kr/sv/SV_svpsbs03V.do?method=view.

[38] G. W. Shin, "An Analysis of Learning Principal in Two Types of Self-directed Learning Purpose”, vol. 1, no. 1, (2012), pp. 35-40.

\section{Authors}

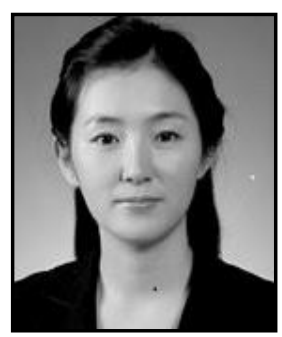

Doo Hyun Jung, she is a $\mathrm{PhD}$., RN, Assisted Professor, Department of Nursing, JinJu Helalth College.

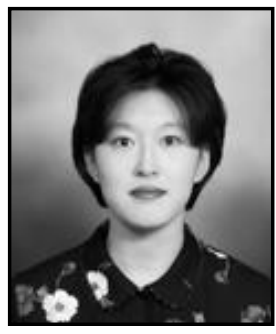

Lee Yun Jeong, she is a PhD., RN, Assisted Professor, Department of Nursing, Kkottongnae University 